\title{
On Risk and Disability - Investigating the Influence of Disability and Social Capital on the Perception and Digital Communication of risk
}

\author{
Jörgen Sparf \\ Department of Social Sciences, Mid Sweden University, SHV, Östersund, 831 52, Sweden \\ E-mail: Jorgen.sparf@miun.se \\ Susanna Öhman \\ Department of Social Sciences, Mid Sweden University, SHV, Östersund, 831 52, Sweden
}

Received 5 January 2014

Accepted 10 February 2014

\begin{abstract}
Does living as a disabled person affect how risks are perceived? Studies of various population groups show that not only macro level structures but also micro social contexts and individual conditions influence risk perception. This knowledge is important for formulating, designing, and communicating risk information. The aim of this study is to examine how $\mathrm{d}$ isabled people's risk perception and pref erence for digit al risk communication channels are influenced by disability in itself and by social capital. A quantitative survey $(\mathrm{N}=6500)$ was carried out in Sweden showing that while disability is not influential, social capital is. This differs from the results of previous studies on other population groups, which show that group specific factors do influence risk perception. This study suggests that due to the importance of social capital, institutions communicating risk information should build strong relationships with (local) disability associations and networks in order to communicate more effectively.
\end{abstract}

Keywords: Disability; risk perception; risk communication; social capital.

\section{Introduction}

Risk is a central aspect of modern life. Much of today's political life and news media revolve around risk-issues and individuals are constantly informed about concerns - from local to global. Not only are timeless risks such as natural hazards, shortages of food and water supplies, and emergen-cies of immediat e interest but also riskissues that are a result of modern lifestyle characterized by affluence, industrial food production, sedentary work and leisure habits, and increased longevity; along with surveillance and cyber risks, macro economic shocks, climate change, urbanization, and the downsides of new technologies.

The pervasiveness of modern risk issues has led to an increased interest in how risks are communicated with the population. To facilitate communicators' and policy makers' decision-making on communication strategies and risk priorities,for example in social work, and for analyzing social vulnerability, knowledge about how people perceive risk is important. In order to prioritize and decide on a cceptable levels of ris $\mathrm{k}$, statistical risk assessments need to be balanced towards perceptions of risk as a reflection of values, for example in order to establish reliability and confidence. Thus, the multidisciplinary research area of ris $\mathrm{k}$ perception has contributed greatly to the understanding and developing of communication about risk and hazard.

The research project 'Risk perceptions and sensemaking of risk in European societies', which this study is part of, focuses on the risk perception of various population groups. Studies show that different ethnic groups, groups of different sexual orientations, and young people perceive risks in different ways compared to a majority of the population (e.g. Olofsson \& Rashid 2011; Wall \& Olofsson 2008). To a large extent these 
differences are explaine $d$ by a com bination of sociostructural differences (income, education, demography, religion etc.) and ind ividual conditions (cognition, emotion, traits etc.). However, some group-specific differences remain after adjusting for these factors. The differences have been found to emerge from variations in fundamental values, the character of risk-related experiences, the effects of structural discrimination, and changing cultural contexts.

As part of the project this study takes a closer look at disabled people. There are two particular reasons for studying disabled people in th is context. Firstly, th e chronological evolvement of sociological risk theory has moved from a soci etal perspective to an organizational governance-perspective (from macro to meso). At the same time, studies of risk perception have evolved the other way, from a co gnitive heuristics perspective to studies of social psychological explanations (from micro to meso). At the point of intersection, where these developments meet, cutting edge research on risk perception is to $b$ e found. Examining group-specific characteristics have proved to contribute to a more nuanced understanding of risk perception, which may serve positive purposes for the group in question. Secondly, in emergency management guidelines various population groups are commonly identified as vulnerable - disabled being one of the most pervasive ones. The research project therefore seeks more knowledge on the risk perceptions of these groups in order to provide knowledge to develop adjusted guidelines.

In everyday life, ris $\mathrm{k}$ is a ub iquitous phenomenon for disabled people. A qualitative study of immobilized people showed that not only where they subject to riskrelated decisions like anyone else, they also had to make constant risk-related decisions directly connected t $\mathrm{o}$ their physical state (Spa rf, 2013). For ins tance, on a daily basis the interviewees choose between avoiding or not avoiding activities and situations referring to their physical abilities, and whether or not to display their disability-related vulnerability. This recurrence of risk in everyday life makes the necessity and utility of social capital more concrete and direct than for many other people. However, disabled people generally have less social capital than non-disabled people (Statistics Sweden 2006; 2009). The combination of a high demand for and low levels of social capital presumably influences how risks are perceived. The research question is therefore whether living as a disabled person really does influence how risks are perceived-if there is a group specific character of risk perception - and whether the level of social $\mathrm{c}$ apital affects how disabled people perceive risks. This knowledge can then be applied by policy makers and practicians in working with social inclusion and safety. If low so cial capital results in high risk perception, fighting social isolation by enhancing the social ca pital can serve as a ris $k$ remedial strategy to reach both actual and perceived personal safety.

The survey in this project focused on self-defined disability. Therefore, a subjective definition of disability is applied (Grönvik 2007; Szebehely, Fritzell \& Lundberg 2001). Since 'definitions of disability' is not the topic of study, the term is used here in a ge neral sense. The effects on risk perception from various specific medical conditions are not examined. The main focus is on general patterns for disabled people as a whole.

Knowledge from risk perception studies are applied in risk information, such as health, environment, and personal security. Authorities, for example, often want to target speci fic groups. So me typical exa mples are: teenagers regarding alcohol, drugs and sexually transmittable diseases; i mmigrants regarding police work and fire safety; middle aged men about prostate cancer; and disabled people about instrumental aid, social services and accessibility. In order to produce risk information that can $\mathrm{b}$ e appropriately assimilated by individuals in different targeted groups, knowledge is needed of how perceptions vary and what is influencing the perception. By the same token, misunderstandings and disinformation can possibly be identified and corrected.

Knowledge regarding group-specific effects on risk perception is valuable when formulating, designing and communicating risk information, for example, what to stress in texts, what photos and illustrations to choose, and what channels of communication should be used From a civil rights perspective, all people have the right to get appropriate risk information communicated in an accessible way (Olofsson 2007). However, Swedish authorities have seldom taken measures to adapt risk communication to match the nee ds of people with different types of i mpairments (Sparf, forthcoming[b]) even though digital communication offers a hug e potential for adjustments. To create a ba sic knowledge 
of the demand for digital communication, the preference of disabled people to use various digital channels for risk information is also studied.

In short, the aim of the study is to examine how disabled people's risk perception and preference for digital risk communication channels is influenced by disability and by social capital

\section{Risk Perception}

The concept of risk perception refers to the subjective mindset and attitudes regarding risks (Slovic 2000). These attitudes, which are $\mathrm{m}$ ore or less exp licitly articulated in judgements regarding the characteristics and severity of risks, are derived from and expressed in individual concerns and needs in various situations and fields of interests.

It is well established that, in a given population, risk perception differs between various groups (Olofsson and Rashid 2011). Studies of gender, age, various ethnicities, and urban-rural residency show that groupspecific factors such as cultural values, experiences, and physical contextual features all infl uence risk perceptions.

In disability research, studies of risk perception are lacking. Risk-related studies primarily concern specific conditions such as learning disabilities, and mental and cognitive conditions (e.g. Alaszewski\&Alaszewski 2002; Dowse 2009; Heyman \& Huckle 1993; Seale \& Ni nd 2010), or more sociological issues, such as marginalization, normalization, independence, equality, and gender (French Gilson 2004; Barron 2001; Kvalsund and Velsvik Bele 2010; Gustavsson 2005), economy and em ployment (Mouridsen and Hauschild 2009; Zissi et al. 2007), violence and crime (Cederborg and Gumpert 2010; Johnston 2002; Olsvik 2006), depression and suicide (Meltzer et al. 2012), and living conditions (Tøssebro and Kittelsaa 2004).

One long-standing debate concerns how subjective risk perceptions come about - what factors influence how various risks are perceived? Possible explanations are often divided into three major schools: cognitive/psychometric, social/cultural, and interdisciplinary. The cognitive school argues that risk perception is to be understood in terms of information processes (Tversky and Kahneman 1974). People use cognitive heuristics in sorting and sim plifying information, which leads to biases in comprehension (e.g. Finucane et al. 2000). A more developed version, the psychometric paradigm, adds a num ber of explanatory factors, such as dread, newness, and stigma to understand the complexity of risk perception (Slovic, Fischhoff, and Lichtenstein 2000; Slovic 2000).

The cognitive/psychometric school focuses on mental aspects and moves away from co gnition only as far as understanding the relative influences of different kinds of knowledge e.g. intuitive knowledge, formal knowledge, and social learning. Recently though, the paradigm has been expanded with research concerning the emotional perspectives on risk perception (Slovic 2010).

In 1982 Mary Douglas and Aaron Wildavsky added social construction arguments to the risk $\mathrm{p}$ erception debate, primarily drawing on 'Cultural Theory' (Adams 1995; Douglas 1985; 1992; Douglas and Wildavsky 1982; Lupton 1999) and the grid-group framework (Douglas 2003). This approach argues that risk perception is highly affected by constraints in the individual's social roles and by feelings of solidarity towards groups that he / she belongs to (Wildavsky and Dake 1990). In these constraining structures of grids and groups, risk perceptions are socially constructed by social institutions and cultural values.

The third school is an attemp $t$ to in tegrate research from psychology, sociology, anthropology, and communications theory in order to present a ge neral model for risk perception. The Social Amplification of Risk Framework (SARF) shows how risk information is communicated through a number of individual and social 'stations' such as experiences, social groups, government agencies, and news media (Renn et al. 1992; Pidgeon, Kasperson, and Slovic 2003). All of these stations act as filters $b$ y amplifying or attenuating the information with reference, for example, to heuristics, values, politics, and social and societal considerations. Both the amplification/attenuation process itself and the actual 'outcomes' - financial losses, regulatory actions, organizational changes, changes in confidence etc. - are believed to influence the individual perception of risks (Pidgeon, Kasperson, and Slovic 2003).

Although all three schools significantly contribute to the explanation of risk perception, one level of analysis is $\mathrm{m}$ issing. While the individual level is covered by cognitive explanations and the macro level by the interdisciplinary research, po ssible explanations between these two levels has not been covered. This could be achieved by examining the individual's social 
capital and its influence on risk perception. This factor is to be found on a $\mathrm{m}$ eso level and concerns the individual resources and context in terms of the physical, emotional and social life- in short, the intimate (social) life of every day. Social capital see ms to fall between the cognitive/psychometric paradigm and th $e$ social/cultural paradigm. SARF does include 'social context' as a component in the individual 'station' but the content of th e component is neither thoroughly explained nor defined with reference to any specific analytic level

\section{Social Capita}

Theories of social capital have been formulated and adapted in se veral academic disciplines, ranging from Coleman's individual approach (Coleman 1988), via Bourdieu's class- and culture-perspective (Bourdieu 1984; 1986), to Putnam's focus on issues of social cohesion and democracy (Adkins 2008; Putnam 1995; 2002). One common objective, regardless of discipline and perspective, is to understand and describe the interaction between social structures and social behaviour (Cook, Burt, and Lin 2001; Lin 1999, 2002).

Most scholars argue that social capital boils down to networks, trust, and norms of reciprocity (Lin 1999; Isham, Kelley, and Ramaswamy 2002; Skrabski, Kopp, and Kawachi 2003; Staveren 2003). To gain access to the capital embedded in s ocial networks, time and commitment are needed. Since this entails some sort of risk-taking, trust is a fundamental prerequisite for every investment initiative. Trust primarily refers to in tegrity and confidence, but also concerns norms of reciprocity - all members of the network expect more or less explicitly to get something in return. When these norms work smoothly, the strength of the network is enhanced.

Networks are basically related to how many people an individual knows and the kind of relationships. Several categorizations of social relations are prevalent in empirical research: family, friends, ac quaintances, co-workers, neighbours etc. Granovetter (1973) distinguishes between strong ties and weak ties i n network relations. While strong ties refer to tight relations in well-defined groups, for example a family, a criminal gang, some close friends or co-workers, weak ties refer to relations between groups as well as between 'second order' relations, acquaintances, a friend of a friend etc.
A similar but more functionalistic approach is taken by Putnam (1995) who distinguished between bridging social capital and bonding social capital. Bridging is the connectedness that is formed across diverse social groups, while bonding refers to the cementation of homogenous groups.

Trust is usually divided into private trust and public trust. Private trust concerns the individual's trust in other individuals, for instance regarding people's intentions and whether they actually act ou these intentions. Public trust refers to the expectations of public organizations, for instance the efficient delivery of appropriate services, and the fair and legal handling of cases (e.g. within s ocial security or the judicial system). In sociological theory this division of trust is commonly called individual trust and system trust (Giddens 1991; 1990). In so cial capital research, MacGillivray and Walker (2000) call them informal and formal trust, Uphoff and Wijayaratna (2000), cognitive and structural trust, and Stone (2002), social and civil/institutional trust, respectively. This study adheres to these divisions by examining trust in people and trust in institutions.

Finally, norms of reciprocity, refer to the expectations and practices among network members regarding the flow of knowledge and information (Dekker and Uslaner 2001; Woolcock 1998). The types of exchanges in this flow spans from hands-on practical favours and help, to in tangible confidence concerning thoughts, ideas, feelings, experiences etc. Exchanges are not to be understood as one-to-one or type-to-type, but rather they are c ontinuously and dynam ically intertwined in a co mplex weave of bo th explicit and tacit reciprocal exchanges. In some texts it is difficult to see the distinction between trust and norms of reciprocity. The distinction can be illustrated by a bank metaphor (cf. Portes 1998). Trust means that the ba nk stores your money safely, while reciprocity refers to the mutual interest for you (e.g. return on investments) and for the bank (e.g. shares of th e return). In this study reciprocity is operationalized by measuring regular contacts with fam ily, friends and neighbours, and whether or not there is someone to turn to for practical help or emotional support.

The interrelatedness between social capital and disability is $\mathrm{w}$ ell established. This study is $\mathrm{b}$ ased in Sweden, where statistics sh ow that both the structural and individual resources of disabled people are 
generally lower than for non-disabled people (Statistics Sweden 2006; 2009). This could be explained by the fact that the majority of disabled people are elderly (National Board of Health and Welfare 2011; Szebehely, Fritzell and Lundberg 2001) and that the bulk of social capital becomes less with o lder age (Statistics Sweden 2006; 2009). International studies of social capital show that the further north and west in Europe, the higher the social capital (Carlsson 2004; Kääriäinen \& Lehtonen 2006; Pichler \& Wallace 2007(Oorschot, Arts, and Gelissen 2006)). Considering the similarity in cu lture and level of welfare in th e Nordic countries, it is plausible to assume that the national distribution of social capital betwee $\mathrm{n}$ various groups is comparable, which would therefore also apply to the results of th is study.

\section{Risk Communication as an Accessibility Issue}

One practical matter connected to risk perception is how information about risks is communicated in an effective way. Matters of risk communication have to a large extent been studied from a sender-perspective, e.g. public bodies and private companies, and a wide range of aspects related to communication has been adapted to a risk and crisis context (c.f. Heath and O'Hair 2009). In spite of the vast research-based body of knowledge concerning variations in risk perception, organizations have treated the communication of risk and crisi $\mathrm{s}$ information rather uniformly. A co mmon statement is 'equal information for everyone' (Olofsson 2007). In this article a slightly different approach is taken by addressing the question of the preferred digital communication channel from a receiver-perspective.

Physical and mental conditions could affect a person's ability to assimilate information. Although a wide selection of ad justable digital hardware and software that can facilitate th $\mathrm{e}$ transfer of vital information is av ailable, it is sel dom used fo $r$ risk information (Sparf, forthcoming[b]). The reasons include a lack of knowledge about the needs from the receiver-side, and $\mathrm{t}$ hat, public bodies and other organizations on the sender-side are reluctant to invest in technology if it does not realistically meet the needs from the receiver-side (Ibid.). By studying the disable $\mathrm{d}$ as a $\mathrm{g}$ eneral target group, knowledge is $\mathrm{g}$ ained that could highlight the possible changes needed for the communication strategies of organizations.

\section{Method}

As part of the research project 'Risk perceptions and sense-making of risk in European societies' the authors and colleagues at the Risk a nd Crisis Research Centre, Mid Sweden University, developed and coordinated the survey 'Society and Values'. The main idea for the survey was to explore connections between risk perception, risk information, risk behaviour, values, and resources, specifically looking at various groups of people. This study is part of the project.

The survey is based on a number of earlier surveys (primarily Enander and Joh ansson 2002; Warg and Wester-Herber 2001; Sjöberg 2000) and a pilot study of five focus group interviews (Olofsson, Öhman, and Rashid 2005). As a consequence the survey consisted of well-established items and qu estions regarding risk issues, as well as completely new ones.

Risk perception was measured through 16 claims about risk-posing threats to th $\mathrm{e}$ individual that respondents were to take a stand on (Sjöberg 2000). No specific type of risk was fo cused on in t he survey rather the set of questions comprised a vast range from accidents during leisure time activities and smoking, to climate change and terrorism. The majority of common risk typologies were covered in the survey: individualcollective, local-global, short term -long term, rapid onset-slow onset, and influenceable-not influenceable.

The answers indicated the respondent's estimates of risk of harm, which by using factor analysis formed three factors: known risks, controllable risks and dread risks. Examples of 'known risks' are the individual's risk of having a traffic acci dent or devel oping cancer, examples of 'controllable risks' are drinking alcohol and smoking. Dread risks are risks which are not easily controllable and which pose a wider threat to humans, such as climate change and terrorism. These factors are taken from a l ong-standing research study on risk perception (e.g. Slovic, Fischhoff, and Lichtenstein 2000).

The questions on social capital were derived from surveys and reviews with empirical evidence of stabile measuring (Harper 2001; Spellerberger 2001; Eriksson 2003; Ruston and Akinrodoye 2002). Following this level of analysis and the three social capital dimensions, a range of questions re garding everyday life were chosen. Table $1 \mathrm{~s}$ hows the indicators and $\mathrm{t}$ he operationalization. 
Table 1 Operationalization of variables.

\begin{tabular}{lll}
\cline { 2 - 3 } Independent variables* & Ondicators & Operationalization \\
\hline \multirow{2}{*}{ Social network } & Activities & $\begin{array}{l}\text { Regular attendance at organized events and visits to public } \\
\text { events/places. }\end{array}$ \\
\cline { 2 - 3 } Trust & Regular contacts & Amount of contact with family, friends and neighbours. \\
\hline & $\begin{array}{l}\text { Trust in people } \\
\text { Trust in } \\
\text { institutions }\end{array}$ & Extent of trust in other people \\
\hline
\end{tabular}

Norms of reciprocity Social inclusion Feelings of being part of, or belonging to, the society/community.

\begin{tabular}{|c|c|c|c|}
\hline \multicolumn{4}{|c|}{ Dependent variables } \\
\hline \multirow{6}{*}{$\begin{array}{l}\text { Risk } \\
\text { perception }\end{array}$} & \multirow{3}{*}{$\begin{array}{l}\text { Individual } \\
(54.4 \% \\
\text { explained } \\
\text { variance })\end{array}$} & Known risks & E.g. the risk of having a traffic accident or developing cancer. \\
\hline & & Controlled risks & E.g. drinking alcohol and smoking. \\
\hline & & Dread risks & E.g. climate change and terrorism. \\
\hline & \multirow{3}{*}{$\begin{array}{l}\text { Societal } \\
(55.6 \% \\
\text { explained } \\
\text { variance })\end{array}$} & $\begin{array}{l}\text { National welfare } \\
\text { risks }\end{array}$ & $\begin{array}{l}\text { School quality, financial crisis, ageing population, living conditions, } \\
\text { corporate migration, children without moral standards, public health. }\end{array}$ \\
\hline & & International risks & $\begin{array}{l}\text { Environmental hazards, nuclear power, unknown illnesses, chemical } \\
\text { accidents. }\end{array}$ \\
\hline & & Global challenges & Migration, population growth, religious fundamentalism. \\
\hline \multicolumn{2}{|c|}{ Risk Communication } & $\begin{array}{l}\text { Digital } \\
\text { information } \\
\text { channel }\end{array}$ & $\begin{array}{l}\text { Assumed use of: webpages, SMS, email, and expert via } \\
\text { email/webpage for getting risk information. }\end{array}$ \\
\hline
\end{tabular}

* Income was also included in the analysis of capital.

Personal characteristics known t o influence risk perception were included as control variables: sex (male/female), age (six equally sized categories from 16 to 75 years ) and experiences of ris ks-/crisis situations. The last variable was measured by asking if the respondent had personal experiences of fire, natural disaster, violence, accidents during leisure time activities, serious diseases or traffic accid ents. The answers were indexed ranging from 0 (none) to 6 (all).

Disability was id entified by asking 'Are you disabled?'.More detailed questions about the respondents' bodily state or quality of disability were omitted from this study for two reasons. Firstly, the aim of the study was to descriptively explore the relation between self-perceived disability and the risk issues in general, not to investigate details on how different kinds of medical conditions influence risk p erception. Secondly, the space allocated in the s urvey for thi $\mathrm{s}$ study was unfortunately extremely limited. The detailed items would simply have required too much space. This is a weakness in the study. There are a number of factors possibly affecting risk perception in various ways, e.g. variations of mental and physical conditions, general degree of disability, root causes for disability etc. To gain deepe $r$ knowledge in this area, future studies would definitely need to include more detailed questions.

The questions on risk communication concerned to what extent a number of digital tools for communicating risk information were likely to be used by the respondent. The answers were given on a five-graded scale ranging from "not likely at all" to "very likely".

A first round of the survey was distributed from November 2005 to January 2006, and a second round in September 2008. For each $r$ ound of the su rvey, a national random sample of postal addresses was selected from Statens pe rsonadressregister (SPAR) ${ }^{*}$, which is an ad ministrative section of the Swedish Tax Agency. The official Regional Ethical Review B oard ${ }^{\dagger}$ investigated the survey and sample without comment.

After reminders by mail and telephone call, the total response rate for each round was $47 \%$, and $39 \%$ respectively. To reach a 1 arger absolute number of disabled respondents, the total of both rounds of the survey was used for analysis. All analyses were ca rried out with dummy variables for the two rounds to ensure

\footnotetext{
*http://www.statenspersonadressregister.se/Om-SPAR/In-English.html ${ }^{\dagger}$ http://www.epn.se/en/start/startpage
} 
that no si gnificant differences between the rounds existed. The respondents were ev enly distributed between men and women and the average age was somewhat older for disabled people (51) than for nondisabled (46).

Eight per cent $(\mathrm{n}=223)$ reported themselves as suffering from disability in some way. Even though different operationalizations of disability in survey research often yields widely varied results (Hugaas Molden \& Tøssebro 2010), for an app lication of selfdefined disability the figure is st rikingly low.Two possible explanations were identified. Firstly, the survey did not explicitly examine disability and included the disability question in the background items. Surveys explicitly dedicated to disability issues might attend more interest from people perceiving themselves disabled - especially if there is reason to believe that the study could enhance the general situation for disabled. Secondly, especially elderly people, among which a vast majority of disabled are found, deterred from taking the survey due to the extensiveness with over 800 items. The lower average age of disabled in this study points at that.

The total response rate of $43 \%$ and 223 disabled respondents is sufficient to analyze whether there were any significant correlations for this group and in what directions they run. However, the low response rate raises a warning that the results and conclusions should be considered more as indications for future research rather than generalizable to a wider population.

\section{Results}

In this section, after a sho $\mathrm{rt}$ description of the small differences in social capita 1 between the groups, a thorough description is given of the connections between social capital vis-à-vis risk perception and risk communication.

Concerning social capital, a gene ral variation between disabled and non-disabled was apparent which confirms the results from other studies. Although the ingroup-variation was high regarding network, in our survey disabled people participated (passively or actively) to a lowe $r$ degree than non-disabled people in activities such as culture, entertainment, sport, religious work, and evening courses (1.74 and 1.96 respectively, index 0-8). Disabled people had a spouse or partner to a lower extent than non-disabled, they lived in smaller households, and had less regular contact with family and friends than the non-disabled (3.98 and 4.05 respectively, index 1-5). Also, disabled people were more alone during leisure time than the non-disabled.

For trust/security the pattern showed th at disabled people had significantly lower general expectations of other people, other peoples' willingness to help, as well as trust in other people (1.79 and 2.15 respectively, index 0-3). The same pattern appeared in relation to trust in institutions, regardless of the type of institution, such as au thorities, political bodies, trade unions, private enterprises, mass media or political parties (3.16 and 3.34 respectively, index 1-5).

Social inclusion also varied between disabled and non-disabled. Disabled respondents regarded the Swedish society to a higher extent as not being open for them. In addition, although they stated that they were living like the average ("normal") Swede, they did not feel as th at they fitted into the community ( 3.35 and 3.37 respectively, index 1-5).

All of these differences are rather sm all, and a s stated earlier is base $\mathrm{d}$ on a s mall sample. However, as all the regressions have the same directions we should pay attention to the differences. Regarding incomes, only $21.6 \%$ of the disabled had an income of more than SEK 20,000 (€ 2,250) per month, compared to $40.9 \%$ for the non-disabled. The a verage income in Swe den year 2008 was SEK 29,275 (€ 3,293) per month (Statistics Sweden 2009).

\subsection{Perception of risks for the individual}

For each of the three risk factors (controllable risks, known risks, and dread risks), only minor differences between the examined groups were found. One interesting finding is th at the in-group variations differed markedly, showing that disabled people were much more scattered in their perceptions than the nondisabled.

The three risk factors were analyzed in relation to social capital (plus income: control group=low income) in a multiple regression (Table 2).

The results clearly show that social ca pital is important for understanding the perception of risks for the individual, especially reg arding controllable risks and dread risks. The only resource with a significantly negative influence on perception in all three risk factors was trust in other people, i.e. the higher the trust in other 
Table 2 Multiple regression: individual risk perception and capital. $(\mathrm{p}=/<0.05$, non significant Beta within brackets). $\mathrm{N}=2805$.

\begin{tabular}{cccc}
\hline & Controllable risks N=2813 & Known risks N=2812 & Dread risks N=2805 \\
\hline Group & & & Beta \\
\hline Disabled people & Beta & Beta & $(0.19)$ \\
\hline Social capital & $(0.01)$ & $(0.02)$ & $(-0.03)$ \\
\hline Activities & & & $-0.02)$ \\
Family & $\mathbf{- 0 . 0 8 8}$ & $(0.01)$ & $(0.00)$ \\
Friends & $\mathbf{- 0 . 0 3 2}$ & $(0.02)$ & $\mathbf{0 . 1 6 3}$ \\
Trust. people & $\mathbf{0 . 0 6 9}$ & $(0.02)$ & $\mathbf{0 . 0 5 3}$ \\
Trust. organizations & $\mathbf{- 0 . 1 2 6}$ & $\mathbf{- 0 . 0 8 7}$ & $\mathbf{0 . 0 8 9}$ \\
Income & $\mathbf{0 . 0 6 1}$ & $(0.02)$ & $\mathbf{- 0 . 0 4 6}$ \\
Social inclusion & $\mathbf{- 0 . 0 6 1}$ & $\mathbf{0 . 0 6 1}$ & $\mathbf{- 0 . 1 2 3}$ \\
\hline Control variables & $\mathbf{- 0 . 0 4 1}$ & $(-0.04)$ & $\mathbf{0 . 1 1 7}$ \\
\hline Sex & & & $\mathbf{0 . 0 8 3}$ \\
Age & $\mathbf{0 . 0 9 3}$ & $\mathbf{- 0 . 0 4 2}$ & 0.070 \\
\hline Experiences of risks & $\mathbf{0 . 0 3 8}$ & $\mathbf{- 0 . 0 4 9}$ &
\end{tabular}

people, the lower the risk perception. Social inclusion showed the same pattern while for trust in organizations, the influence was reverse - th e higher the trust in organizations, the higher the risk perception. Notably, experience of risk also had a strong positive one-way influence.

\subsection{Perception of societal risks}

Concerning societal risks, disabled people had a slightly higher risk perception of all three factors, with the largest being for global challenges; however these results were not significant.

The three risk factors were analyzed in $\mathrm{t}$ erms of social capital (plus income: control group=low income) in a multiple regression (Table 3 ).

Most notable from this table is that, once again, trust is the most dominant factor influencing risk perception.
In addition, activities seem to have some influence - the more socially active a pe rson, the lower the perce ption of international risks and global challenges. Just as in the case of risks for the individual, previous risk experiences had a on e-way positive correlation with societal risk perception.

\subsection{Risk communication}

In line with the other findings, disabled people reported a lower probability of using various information techniques (Table 4).

Once again resources seem to have a high explanation rate. On ly this time income and social inclusion were the resources with th e strongest influence, showing that the higher the income and the higher the feeling of being socially included, the higher the likelihood of using digital risk information channels.

Table 3 Multiple regression: societal risk perception and capital. ( $\mathrm{p}=/<0.05$ non significant Beta within brackets).

\begin{tabular}{rccc}
\hline & National welfare risks N=2811 & International risks N=2812 & Global challenges N=2812 \\
\hline Group & Beta & Beta & Beta \\
\hline Disabled people & $(-0.01)$ & $(0.01)$ & $(0.03)$ \\
\hline Social capital & & & $\mathbf{- 0 . 1 1 3}$ \\
Activities & $(0.01)$ & $\mathbf{- 0 . 0 4 9}$ & $(0.00)$ \\
Family & $(0.03)$ & $(0.00)$ & $\mathbf{0 . 0 4 6}$ \\
Friends & $(0.01)$ & $(0.02)$ & $\mathbf{- 0 . 1 4 6}$ \\
Trust: people & $\mathbf{- 0 . 0 8 7}$ & $\mathbf{- 0 . 0 7 6}$ & $\mathbf{- 0 . 0 9 5}$ \\
Income & $\mathbf{- 0 . 0 8 6}$ & $\mathbf{0 . 0 5 6}$ & $(0.00)$ \\
Trust: organizations & $(0.02)$ & $\mathbf{- 0 . 1 5 0}$ & $(0.02)$ \\
\hline Social inclusion & $\mathbf{0 . 1 0 0}$ & $\mathbf{- 0 . 0 7 5}$ & \\
\hline Sex & & & $\mathbf{0 . 2 1 5}$ \\
Age & $\mathbf{- 0 . 1 4 1}$ & $\mathbf{0 . 0 3 4}$ & $\mathbf{0 . 0 9 3}$ \\
Experiences of risks & $\mathbf{- 0 . 0 4 4}$ & $\mathbf{0 . 0 1 8}$ & $\mathbf{0 . 1 3 2}$ \\
\hline Adjusted R ${ }^{2}$ & $\mathbf{0 . 0 8 5}$ & 0.102 & $\mathbf{0 . 0 3 9}$ \\
\hline
\end{tabular}


Table 4 Multiple regression: assumed use of digital information channel for various risks and capital. ( $\mathrm{p}=/<0.05$ non significant Beta within brackets) $\mathrm{N}=2801$.

\begin{tabular}{|c|c|c|c|c|c|}
\hline & $\begin{array}{c}\text { Domestic fire } \\
\mathrm{N}=2807\end{array}$ & $\begin{array}{l}\text { Leisure time accident } \\
\qquad \mathrm{N}=2807\end{array}$ & $\begin{array}{c}\text { Chemical accident } \\
\qquad \mathrm{N}=2807\end{array}$ & $\begin{array}{c}\text { Epidemics N }= \\
2806\end{array}$ & $\begin{array}{l}\text { Natural disaster } \\
\qquad \mathrm{N}=2806\end{array}$ \\
\hline Group & Beta & Beta & Beta & Beta & \\
\hline Disabled people & $(0.01)$ & $(-0.01)$ & -0.051 & $(0.00)$ & $(-0.02)$ \\
\hline \multicolumn{6}{|l|}{ Social capital } \\
\hline Activities & $(0.02)$ & $(0.01)$ & $(0.01)$ & $(0.02)$ & $(0.01)$ \\
\hline Family & $(-0.02)$ & -0.032 & $(-0.02)$ & -0.032 & -0.057 \\
\hline Friends & $(0.00)$ & $(0.02)$ & $(0.00)$ & $(0.01)$ & $(0.00)$ \\
\hline Trust: people & $(0.00)$ & $(-0.01)$ & $(-0.01)$ & $(-0.02)$ & $(0.00)$ \\
\hline $\begin{array}{r}\text { Trust: organiza- } \\
\text { tions }\end{array}$ & $(0.01)$ & $(0.01)$ & $(0.00)$ & $(0.01)$ & $(0.01)$ \\
\hline Income & 0.089 & 0.103 & 0.042 & 0.066 & 0.060 \\
\hline Social inclusion & 0.299 & 0.268 & 0.215 & 0.314 & 0.286 \\
\hline \multicolumn{6}{|l|}{$\begin{array}{l}\text { Control } \\
\text { variables }\end{array}$} \\
\hline Sex & 0.041 & 0.034 & $(0.02)$ & 0.031 & 0.046 \\
\hline Age & -0.325 & -0.326 & -0.209 & -0.302 & -0.281 \\
\hline $\begin{array}{l}\text { Experiences of } \\
\text { risks }\end{array}$ & -0.037 & -0.036 & $(0.00)$ & -0.035 & -0.050 \\
\hline Adjusted $\mathrm{R}^{2}$ & 0.208 & 0.192 & 0.092 & 0.202 & 0.178 \\
\hline
\end{tabular}

For some risks, the significance of the family seems to matter. The results showed that an intimate relationship with close family results in a lower probability of using the web channels. The regression were definite both for social capital and for the c ontrol variables, where the positive influences were in come and social inclusion and the negative being family, age and experiences of risk.

To sum up, out of 27 capital indicators in the study, 13 had a si gnificant influence on individual risk perception, 12 on societal risk perception, and 13 on risk communication channels. The $\mathrm{m}$ ost influential indicators in the study were social inclusion and income (9 each), then in a falling scale: trust in people (6), trust in organizations (5), family (4), activ ities (3), and friends (2). For risk perception, of the 25 significant correlations, 18 were negative and only 7 positive. This tendency is also the same for trust, which is the social capital component with the biggest influence on risk perception. Out of 11 significant correlations, 8 were negative and only 3 positive. This means that the higher the trust in people and organizations, the lower the risk perception both for the individual and society. Although the analysis is carried out on a small sample and the pvalue of each analysis was rather low, the pattern is clear: social capital does matter and is i mportant in understanding risk perception.

\section{Discussion}

The main finding of the study is that risk perception and the use of digital risk communication channels are affected by social capital but not by disability. This is thus different from previous studies on other population groups that showed that group specific factors do influence risk perception.

The assumption that being disabled affects how risks are perceived has not been empirically confirmed. Regardless of whether a person is disabled from birth or from later in life, the bodily state becomes an integrated part of both the person's identity and everyday life. On the other hand Sparf (2012) shows that stressful, disability-specific situations, revealing vulnerability, do occur in e veryday life which possibly affect ris $\mathrm{k}$ perceptions.

In practical ri sk communication, the disabled are usually treated as a homogeneous target group. However, due to varieties in medical conditions, the ingroup variation is large regarding needs and preferences regarding how to receive risk information and how to facilitate two-way communication. Because of $t$ he non precise nature of th e disability data in this study, 
analyzing in-group differences is not feasible. Therefore the results do not lend themselves to inform adjustments of emergency guidelines, as this would probably require more specific data.

What is possible, however, is a discussion of the implications for communicating with the disabled with regard to the influence of social capital. The pattern from the multiple regressions is quite clear: the $m$ ore social capital an individual can access, the lower the perception of risks and the higher the likelihood of using digital risk information channels. This pattern is discussed below for each of the social capital factors.

Trust is the stronge st social capital factor influencing risk perception. Disabled people generally seem to have a lower degree of trust both in other people and in in stitutions. Since low trust correlates with high risk perception, a reason able implication is that risk communicators must work with trust issues in parallel with risk communication, in order to enhance the effectiveness of the communication.

The function of trust operates on two levels: societal / systemic and interpersonal. The societal / syste mic level concerns (1) trust in modern societal systems of experts and technology (Giddens 1992) and (2) trust as a socio-cognitive mechanism to reduce social complexity in the modern society (Luhmann 1979:150). Social complexity demands individuals to accepta certain amount of uncertainty. In a con stant flow of information trust helps us to rely on the world to functioning without us having a to tal knowledge about everything or to have control over the course of events.

Trust on an interpersonal level, concerns integrative aspects, for instance being part of a community, a social group or a society in general. Parsons (1978) asserts that trust resides in the individual's belief that others will put their self-interest aside in favour of a collective orientation. The in tegration thus refers to attitudes and experienced feelings rather than a factual belonging, e.g. citizenship. Trust can also be a lubricant for cooperation. This is a return to Co leman and his rational choiceinterpretation of social networks. Coleman (1990) assumes that actors are not only rational but a re also unconstrained by norms and are purely self-interested. Trust within a social network serves as a replacement for normative monitoring and sanctioning. This means that the smaller the network, the better the trust serves as a lubricant.
For institutions communicating risk information, both these levels can be approached by establishing reliability and confidence. By b uilding strong relationships with (local) disability associations and networks, they show trustworthiness and consistency. A confident source of in formation is quite simply more likely to be listened to.

The fact that disabled people take part in social activities to a lesser ex tent and have a smaller so cial network raises another challenge for risk communicators. The $\mathrm{c}$ hallenge is not that of reaching disabled individuals $-\mathrm{t}$ his can be acc omplished by personally ad-dressed mail and via radio, television, the internet, email etc. - th e challenge is rather to ensure that the information is fu lly assimilated. The more controversial or important the issue, the more we tend to talk about it with friends and colleagues. By discussing issues, we internalize information and socially construct opinions and knowledge. This process is possibly harder to fulfil for socially disconnected or isolated individuals.

Connecting this reasoning with Granovetter's (1973) assertion on strong and weak ties, risk communicators could make active use of the weak ties in the disability community. For instance, people engaging in disability associations, usually do no $t$ only have strong ties to other highly engaged people but they also know about other disabled people that are less, or not at all, engaged. These weak ties could be utilized as a catalyst for risk communication and ensure that risk information is assimilated within the disability community. The fact that disabled people are formally organized is a strength compared to other groups w ith low social capital. By liaising with local disability associations, subgroups are bridged together (c.f. Putnam 1995), thus enhancing the effectiveness of risk communication.

The third social capital factor in this study, norms of reciprocity, has the function of fostering solidarity and cohesion, and th ereby creating the stability and permanence of the net-work. The collective norms are reinforced by social control and will only function for initiated and active people. This study shows that disabled people are socially included to a lesser extent than the non-disabled. For a socially disconnected person, any reciprocal aspe ct with beari ng on risk information is difficult to collectively reflect upon. Just as for networks, the process of internalizing information and socially constructing opinions and knowledge can 
be hard to achieve. Here too, the aspect of weak ties and relationship-building is relevant for risk communication.

\section{Final remarks:}

Although defining the disabled as a group within a larger population, with regard to socio-economic status, 'disability-culture', or shared experiences can be of theoretical significance, this study does not validate such a definition empirically. Yet th is is continuously done in practical work on risk communication.

As the results from the study indicate,identifying group-specific variables and analyzing their effects can be important in developing effective risk communication. Concerning disabled various medical conditions and i mpairments might affect the ability to assimilate risk information, hence there is a larg e potential to use adapted digital communication channels However, in order to improve risk communication, further research regarding the connections between social capital, risk perception and various impairments are needed.

One limitation of this study is the small number of relevant respondents $(\mathrm{n}=223)$. However, the group is big enough to show a clear pattern of significant correlations in the analysis. In order to validate the results from this study more research would be necessary on a 1 arger sample of disabled people. Another limitation is th at the group is treated as homogeneous. Although the respondents happen to bear a common feature, the in-group variation is probably very wide, both in term s of individuality and types of disability. Therefore, since risk information is often communicated to specific groups, and since the results from the analysis show a m arkedly big in-group variation, a reasonable next step would be to examine any in-group patterns related to risk perception. The more detailed knowledge available, the better adapted the risk information and communication channels will be.

\section{References}

1. Adams, J. 1995. Risk, London: University College London.

2. Adkins, L. 20 08. Social Capital Put to the Test. Sociology Compass, 2(4):1209-1227.

3. Alaszewski, A. andH. Alaszewski, 2002. Towards the creative management of risk: perceptions, practices and policies,British Journal of Learning Disabilities, 30(2): 56-62.
4. Barron, K. 2001. Autonomy in Everyday Life, for Whom? Disability \& Society, 16(3): 431 - 447.

5. Bourdieu, P. 1984. Distinction : a social crit ique of the judgement of taste, London: Routledge.

6. Bourdieu, P. 1986.The forms of capital.In Handbook of Theory and Research for the Sociology of Education, ed. J. Richardson, New York: Greenwood.

7. Carlsson, P. 2004.The European health divide: a matter of financial or social capital? Social Science \& Medicine, 59(9): 1985-1992.

8. Cederborg, A-C. And C.H. Gumpert, 2010. The challenge of assessing credibility when children with intellectual disabilities are alleged victims of abuse. Scandinavian Journal of Disability Research, 12(2): 125 - 140.

9. Coleman, J. S. 1988. Social Capital in the Creation of Human Capital. The American Journal of So ciology (Supplement: Organizations and Institutions: Sociological and Economic Approaches to the Analysis of Social Structure), 94: 95-120.

10. Coleman, J. S. 1990. Foundations of So cial Theory. Cambridge, Mass: Harvard University Press.

11. Cook, K., Burt, R. S. And N. Lin, 2001 .Social capital : theory and re search, Sociology and economics. New York: Aldine de Gruyter.

12. Dekker, P. andE.M. Uslaner, 2001. Introduction. In Social Capital and Participation in Everyday Life. Ed. P. Dekker and E. M. Uslaner, London: Routledge.

13. Douglas, M. 19 85.Risk acceptability according to the social sciences. New York: Russell Sage Foundation.

14. Douglas, M. 20 03. Natural symbols : explora tions in cosmology. London: Routledge.

15. Douglas, M. an d A. Wild avsky, 1982. How C an We Know the $\mathrm{R}$ isks We Face? Why Risk Selection Is a Social Process. Risk Analysis, 2(2): 49-51.

16. Dowse, L. 2009. Some people are never going to be able to do that: Challenges for people with intellectual disability in the 21st Century. Disability\& Society, 24(5): 571-584.

17. Enander, A, and A. Johansson,2002.Säkerhet och risker $i$ vardagen: en studie av uppfattningar, värderingar och beteenden hos allmänheten $i$ Sverige [Safety and risks in everyday: a study of perceptions, values, and behaviours among the public in Sweden]. Karlstad: Räddningsverket.

18. Eriksson, M. (2003) Socialt kapital. Teori, begrepp och mätning - en ku nskapsöversikt [Social capital. Theory, 
terms, and measurement - a knowledge $\mathrm{r}$ eview]. CERUM, Working Paper, 60.

19. Finucane, M. L. , Alhakami, A., Slovic, P, andS.M. Johnson, 2000. The affect heuristic in judgments of risks and benefits. Journal of Behavioral Decision Making, 13(1): 1-17.

20. Flap, H. andB. Völker, 2004 .Creation and $r$ eturns of social capital: an ew research program. London: Routledge.

21. French Gilson, S. 2004. Disability, Identity, and Cultural Diversity. Review of Disability Studies, 1(1): 16-23.

22. Giddens, A. 19 90.. The consequences of modernity . Cambridge: Polity in association with Blackwell.

23. Giddens, A. 1991. Modernity and Self-Identity. Cambridge: Polity Press.

24. Giddens, A. 1 992.The transformation of I ntimacy: sexuality, love and eroticism in modern societies. Cambridge: Polity Press.

25. Granovetter,M. 1973. The Strength of Weak Ties. The American Journal of Sociology78(6): 1360-1380.

26. Grönvik, L. (20 07) Definitions of Disability in Social Sciences : Methodological Perspectives. Uppsala: ActaUniversitatisUpsaliensis. PhD diss.

27. Gustavsson, A. 2005.Resistance, reflection and change : Nordic disability research, Social research on disability. Lund: Studentlitteratur.

28. Harper, R. 2001.Social Capital. A Review of the Literature. Newport: Office for National Statistics.

29. Heath, R. L.and D. O'Hair, 2009.Handbook of risk and crisis communication. New York: Routledge.

30. Heyman, B. and S. Huckle, 1993. Not worth the risk? Attitudes of adults with learning difficulties, and their informal and formal carers to the hazards of everyday life.Social Science \& Medicine, 37(12): 1557-1564.

31. HugaasMolden, T. And Tøssebr oJan, 2010. Measuring disability in survey research: Comparing current measurements within one data set. ALTER European Journal of Disability Research, 4 (2010), pp. 174-189.

32. Isham, J., Kelley, T. andS. Ramaswamy, 2002. Social capital and well-being in developing countries: an introduction. In Social Capital and Economic Development: Well-being in Developing Countries. Ed S. Ramaswamy,Cheltenham: Edward Elgar.

33. Johnston, S.J. 2002. Risk a ssessment in offenders with intellectual disability: the evidence base. Journal of Intellectual Disability Research, 46 (supplement s1): 47-56.
34. Kvalsund, R. andI. Velsvik Bele, $2010 \quad$.Adaptive situations and social marginalization in early adult life: students with special educational needs. Scandinavian Journal of Disability Research, 12(1): 59 - 76.

35. Kääriäinen, J. andH. Lehtonen, 2006.The variety of social capital in welfare state regimes - a comparative study of 21 countries. European Societies 8(1): 27-57.

36. Lin, N.1999. Building a Netw ork Theory of Social Capital. Connections, 22(1): 28-51.

37. Lin, N. 2002.Social capital : a theory of social structure and action. New York: Cambridge University Press.

38. Luhmann, N. 1979.Trust and Power: two works. Chichester: Wiley.

39. Lupton, D. (ed .) 1999.Risk and soc iocultural theory. New directions and perspectives . Cambridge: Cambridge university press.

40. MacGillivray, A. andP. Walk er, 2000. Local Social Capital: Making it Work on the Ground. InSocial Capital: Critical Perspectives, ed T. SchullerOxford: Oxford University Press.

41. Meltzer, H., Brugha, T., Dennis, M. S., Hassiotis, A., Jenkins, R., McManus, S., R ai, D., and Bebbington, P. 2012. The influence of $d$ isability on suicidal behaviour.ALTER European Journal of D isability Research, 6 (2012) pp. 1-12.

42. Mouridsen, S. E. andK-M. Hauschild, 2009 . Disability pensions in individuals diagnosed with a developmental language disorder as children. Scandinavian Journal of Disability Research, 11(4): 275 - 285.

43. National Board of Health and Welfare. 2011.Funktionshindradepersoner - insatserenligt LSS år 2010 [Persons with Certain Functional Impairments measures specified by LSS 2010]. Stockholm: NationalBoard of Health and Welfare.

44. Olofsson, A.,Öhman, S. andS. Rashid, 2005. Views of risk in late modernity: Do people's view of risk define our time? Conference paper, International Sociological Association: Environment, Knowledge and Democracy, July 6-7, 2005, at Facu lty of sciences of Lumin y, Marseille.

45. Olofsson, A. 2007.The $P$ reparedness of Local Authorities for Crisis Communication with People Who Have Foreign Backgrounds: The Case of Sweden. International Journal of Mass Emergencies and Disasters, 25(2): 145-160.

46. Olofsson, A. and S. Rash id,2011. The White (M ale) Effect and Risk Perception: Can Equality Make a Difference?Risk Analysis, 31(6): 1016-1032. 
47. Olsvik, V. M. 2006. Vulnerable, Exposed and Invisible: A Study of Violence and Abuse against Women with Physical Disabilities. Scandinavian Journal of Disability Research, 8(2): 85 - 98.

48. Oorschot, Wim van, Wil Ar ts, and John Gelissen. 2006. "Social Capital in Europe: Measurement and Social and Regional Distribution of a Multifaceted Phenomenon." Acta Sociologica 49:149-167.

49. Parsons, T. 1978.Research with human subjects and the professional complex. New York: Free Press.

50. Peters, S. 200 0.Is There a Disability Culture? A Syncretisation of Three Possible World Views.Disability \& Society, 15(4): 583-601.

51. Pichler, F. andC. Wallace,2007. Patterns of Formal and Informal Social C apital in Europe. European Sociological Review, 23(4): 426-435.

52. Pidgeon, N. F., Kasperson, R. E. andP. Slovic, 2003.The social amplification of risk. Cambridge: Cambridge University Press.

53. Portes, A. 19 98. Social Capital: Its Origins and Applications in Modern Socio logy. Annual Review of Sociology, 24: 1-24.

54. Putnam, R. D . 1995. Bowling alone: America' s Declining Social Capital. Journal of Democracy, 6(1): $65-78$.

55. Putnam, R. D. 2002.Democracies in flux : the evolution of social capital in contemporary society. Oxford: Oxford University Press.

56. Renn, O, Burns, W. J., Kasp erson, R. E. andP. Slovic, 1992. The social amplif ication of risk: theoretical foundations and empirical allocations. Journal of Social Issues, 48(4): 137-160.

57. Ruston, D. andL. Akinrodoye, 2002.Social Capital Question Bank. Questions from Social Capi tal surveys included in the Socia l Capital Survey Matrix 2002. Newport: Office for National Statistics.

58. Seale, J. and M. Nind , 2010.Understanding and promoting access for people with learning difficulties: seeing the opportunities and challenges of risk.London: Routledge.

59. Sjöberg, L. 20 00. Factors in Risk Percep tion. Risk Analysis, 20(1): 1-12.

60. Skrabski, A, Kopp, M. and I . Kawachi,2003. Social Capital in a Changing Society: Cross Sectional Associations with Middle Aged Fem ale and Male Mortality Rates. Journal of Ep idemiology and Community Health, 57(2): 114-119.
61. Slovic, P. 20 00.The perception of risk. London: Earthscan.

62. Slovic, P. 2010.The feeling of risk : new perspectives on risk perception. London:Earthscan.

63. Slovic, P. Fischhoff, B. And S. Lichtenstein, 2000. Cognitive Processes and Soc ial Risk Taking. In The Perception of Risk, ed. P. Slovic, London: Earthscan.

64. Spellerberger, A. 2001.Framework for the Measurement of Social Capital in New Zealand. Wellington: Statistics New Zealand.

65. Statistics Sweden 2006 and 2009. Undersökningarna av levnadsförhållanden (ULF) [Surveys about living conditions].

http://www.scb.se/Pages/SubjectArea___12184.aspx.

66. Staveren, I. van 2003. Beyond Social Capital in Poverty Research. Journal of Economic Issues, 37(2): 415-424.

67. Stone, W. And J. Hughes, 2002.Social capital: empirical meaning and measurement validity. Research Paper No. 27. Melbourne: Australian Institute of Family Studies.

68. Szebehely, M., Fritzell, J . andO. Lundberg, 2001.Funktionshinderochvälfärd.SOU 2001:56 [Disability and Welfare]. Stockholm: Fritzes.

69. Tversky, A. andD. Kahneman,1974. Judgment under Uncertainty: Heuristics and Biases. Science, 185(4157): 1124-1131.

70. Tøssebro, J. andA. Kittelsaa, 2004.Exploring the living conditions of disabled people, Social research on disability. Lund: Studentlitteratur.

71. Uphoff, N. andC.M. Wijayaratna, 2000. Demonstrated Benefits from Social C apital: The Productivity of Farmer Organizations in Gal Oya, Sri Lanka. World Development, 28: 1875-1890.

72. Wall, E.And A. Olofsson, 2008. Young people making sense of $r$ isk: How meanings of risk are materialised within the social context of every-day life.Young Nordic Journal of Youth Research.16(4): 431-448.

73. Warg, L-E. andM. Wester-Herber, 2001.Riskkommunikation. Att implementera Seveso IIdirektivet i Sverige [Risk communication. Implementing the Seveso II Directive in Sweden], Karlstad: Räddningsverket.

74. Wildavsky, A. andK. Dake, 1990. Theories of $r$ isk perception: who fears what and why. Doedalus, 119(4): 41-60.

75. Woolcock, M. 1998. Social Capital and Economic Development: Toward a Th eoretical Synthesis and Policy Framework. Theory and Society, 27(2): 151-208. 
76. Zissi, A., Ronto s, C., Pap ageorgiou, D., Pierr akou, C. And S. Chtouris, 2007. Greek Employers' Attitudes to Employing People with Disabilities: Effects of the Type of Disability. Scandinavian Journal of Disability Research, 9(1): 14 - 25.

77. Sparf, J. (2013a ccepted) Disability and Vulnerability : Interpretations of Risk in Everyday Life.Journal of Contingencies and Crisis Management.

78. Sparf, J. (Forthcoming[b], submitted) A parasite to care about : Integrating a freshwa ter contamination with the everyday work of a caring organization 